\title{
Design and Modeling of S Band Circular Patch and Ka Band Horn Antenna, Integration with Future Multifunctional Radio over Fiber Network
}

\author{
Rao Kashif*, Oluwole John Famoriji, Fujiang Lin \\ Department of Electronic Science and Technology, University of Science and Technology of China, Anhui, China \\ Email: *raokashif47@yahoo.com
}

How to cite this paper: Kashif, R., Famoriji, O.J. and Lin, F.J. (2017) Design and Modeling of S Band Circular Patch and Ka Band Horn Antenna, Integration with Future Multifunctional Radio over Fiber Network. Open Journal of Antennas and Propagation, 5, 121-131.

https://doi.org/10.4236/ojapr.2017.53010

Received: August 17, 2017

Accepted: September 22, 2017

Published: September 25, 2017

Copyright $\odot 2017$ by authors and Scientific Research Publishing Inc. This work is licensed under the Creative Commons Attribution International License (CC BY 4.0).

http://creativecommons.org/licenses/by/4.0/

\begin{abstract}
Radio over Fiber is an integration of microwave and optical fiber technologies having numerous benefits. RoF technology can give a scope of advantages including the capacity for backing multiple radio services and standards. In coming future, there is need of integrated wireless service with high speed satellite broadband and multifunctional indoor/outdoor antennas. Radio over fiber is one of the most favorite candidates to meet all these requirements of future multifunctional integrated wireless communication. Due to planer profile, small size and low cost patch antennas are most favorite to use for multi-frequency applications. In this paper, we present system level design for future multifunctional radio over fiber network. Under FTTH (Fiber To The Home) technology, it will be possible to use multi-frequency applications on single fiber medium. Firstly, we designed $\mathrm{S}$ band circular patch antenna (2.5 $\mathrm{GHz})$ and $\mathrm{Ka}$ band $(29 \mathrm{GHz})$ horn antenna. Circular patch antenna performance is estimated with different substrate height. After getting $\mathrm{S}$ parameters and far-field results, we did modeling of Radio over Fiber system over (10 $\mathrm{Km}$ ) with same parameters from antenna results.
\end{abstract}

\section{Keywords}

Radio over Fiber, S-Band, Ka-Band, March Zehnder Modulator, CW Laser

\section{Introduction}

Future high speed wireless communication is based on millimeter waves but High Air link loss reduces the communication distance in millimeter wave systems. Radio over fiber is one good technology to extend the coverage in which Rf 
signal transmitted through optical fiber. Radio over Fiber is just sending the radio signals over optical fiber. Easy maintenance, low power units, simple remote antennas, low attenuation loss, large bandwidth and reduced power consumption are few benefits of RoF link. RoF is an auspicious solution to accomplish the increasing demand of wireless and user bandwidth. In RoF system, the only task of Base station is to convert optical signal into Radio signal. In recent advancement laser, photodiode and circulator are replaced with a single electronic device called electro absorption modulator [1]-[7]. EAM acts as photodiode for downlink and modulator for uplink. No light source is needed at RAU which makes it much simpler and cheaper. In 2012, A. Kumar \& N. Agarwal worked on RoF integration microwave and optical communication was accessible to broadband wireless communications [6]. Three methods are implemented into RoF and compared with Attenuation: Scattering, BER and CNR. Satellite communication, mobile radio communication, broadband and wireless LAN are few more applications of RoF [3] [5] [6]. Radio-over-fiber (RoF) is an attractive technology for multi broadband services [8]-[16].

Due to light weight, low cost and small size, micro strip antennas are getting popular for future high speed communication. Most commonly used patch antennas are circular and rectangular shaped antennas. In triangular shape antenna, bandwidth is the biggest problem in many applications. Because of this factor, circular patch antennas are widely used in numerous wireless communications [17] [18]. Micro strip antennas are always preferred for integrated wireless applications due to its broad bandwidth for maximum performance [19].

In this paper, we first designed $\mathrm{S}$ band $(2.5 \mathrm{GHz})$ circular patch antenna and $\mathrm{Ka}$ band $(29 \mathrm{GHz})$ horn antenna. Antennas were designed and simulated in CST 2017 and after performance analysis, S parameters were imported in Optic System 14 via MATLAB file. Both $(2.5$ and $29 \mathrm{GHz})$ antennas $\mathrm{S}$ parameters were simulated in multi frequency RoF network for indoor communication. Figure 1 shows a typical RoF network for indoor communication.

\section{Antenna Design}

Future RoF needs multi-functional and multi-frequency antennas, because indoor wireless applications work on different frequencies. To do RoF system demonstration we designed two different frequencies antenna and use parameters for RoF system simulation.

\subsection{S band Circular Patch Antenna (2.5 GHz)}

Circular patch antennas are attention seekers in both single elements [20]-[25] and in arrays [26] and [27]. Cavity Model [21] [24] [25] can be used for conveniently analysis of circular patch antenna. Circular patch antenna occupies less space as compared to rectangular patch antenna. We deigned $2.5 \mathrm{GHz}$ circular patch antenna and get S parameters. Design Parameters of antenna is shown in Figure 2. Due to low cost and small size such antenna can be used for multi- 


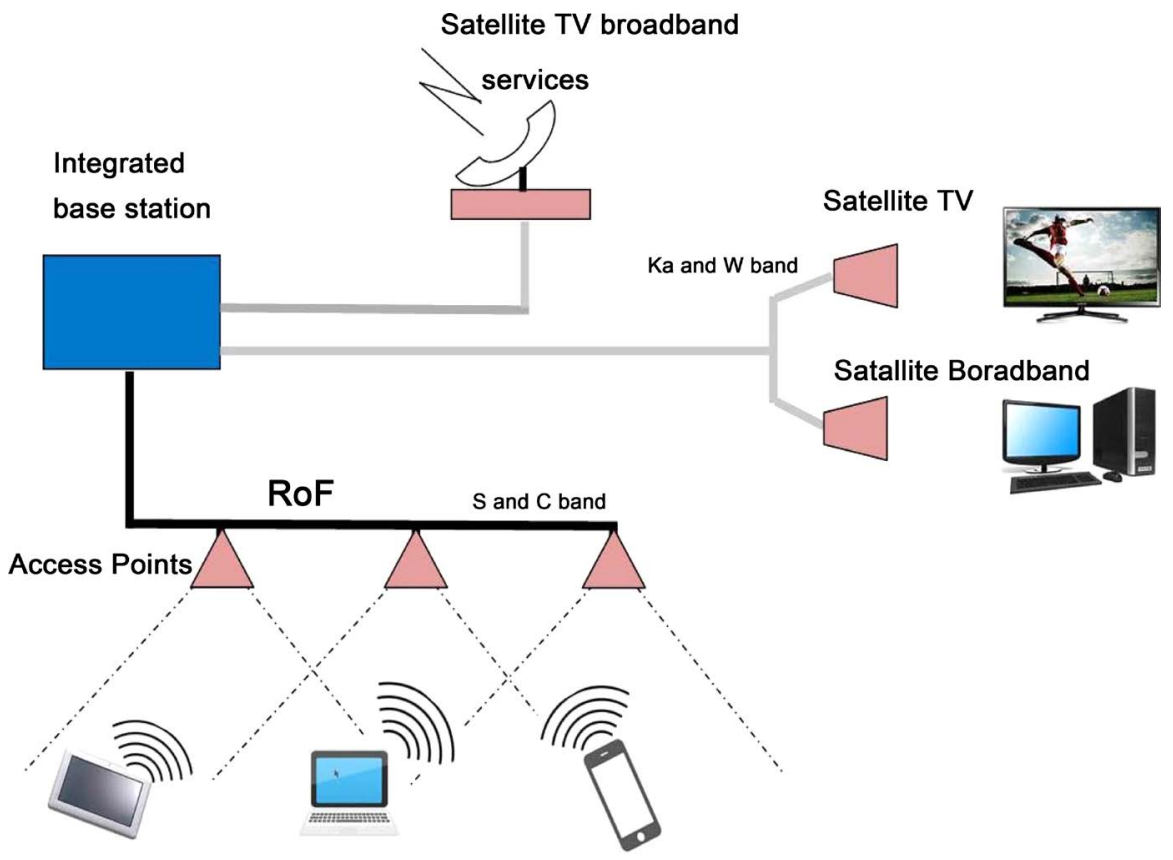

Figure 1. Radio over Fiber Integrated Wireless System design.

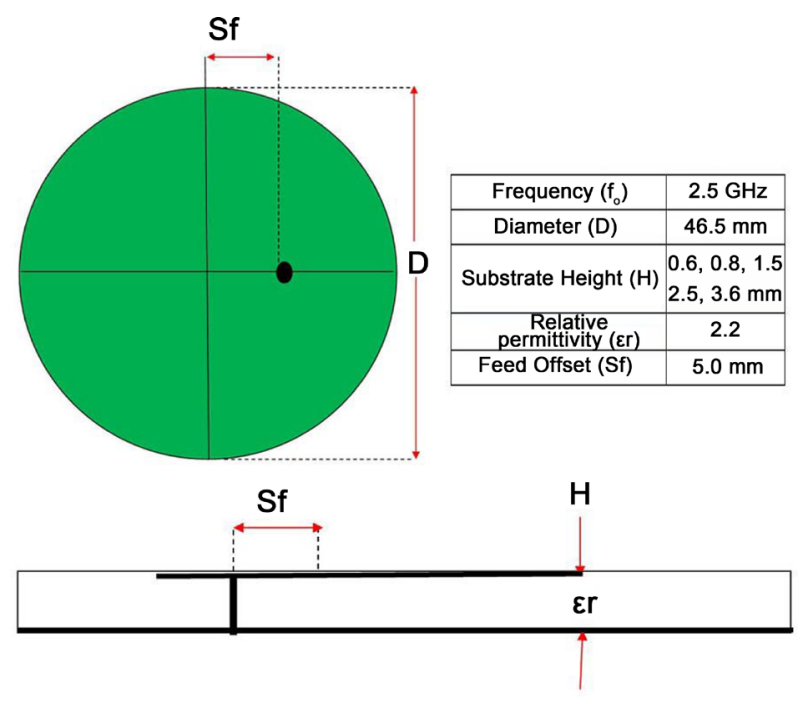

Figure 2. 2.5 GHz Circular patch antenna design parameters.

functional application in future radio over fiber activities. Radius of patch is found by Equation (1) [28] [29].

$$
r_{\text {eff }}=\sqrt[r]{1+\frac{2 h}{\pi r \varepsilon_{r}}\left[\ln \frac{\pi r}{2 h}\right]+1.7726}
$$

where $r=$ physical radius of circular patch

$h=$ height or thickness of the substrate

$\varepsilon_{r}=$ Dielectric Constant.

\subsection{Ka Band Horn Antenna $29 \mathrm{GHz}$}

First horn antenna was constructed by Indian radio researchers in 1897. In 1962 
they become widely used for microwave and satellite antennas. Horn antenna has very little loss so directivity is roughly equals to its gain. Due to absent of resonant elements horn can operate over wide bandwidth. Low SWR, wide band width and simple architecture are advantages of horn antennas. We designed waveguide-fed pyramidal horn antenna for Ka band $(29 \mathrm{GHz})$. This can be used for satellite and broadband application in Radio over fiber network. Parameters of antenna are shown in Figure 3.

\section{Antenna Results}

S parameters show input and output relationship. S11 shows total reflected power from antenna also called reflection coefficient. Figure 4 shows $\mathrm{S}$ parameters for circular patch antenna with different substrate height while Figure 5 shows $\mathrm{S}$ parameters of Ka band Horn antenna.

\subsection{VSWR (Voltage Standing Wave Ratio)}

VSWR (Voltage standing wave ratio) also related to $S$ parameters, smaller the
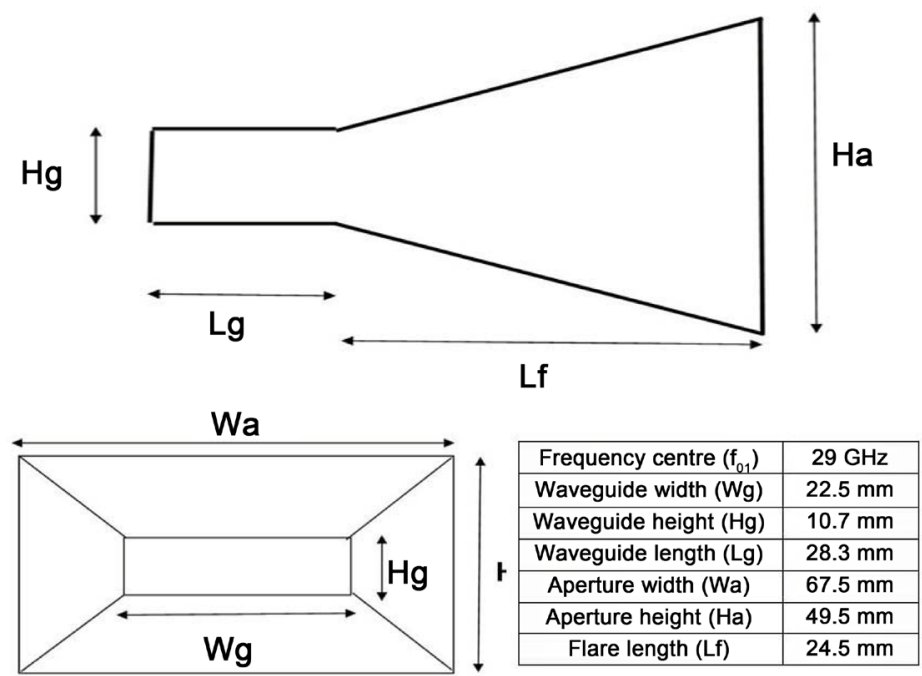

Figure 3. $29 \mathrm{GHz}$ Horn Antenna design parameters.

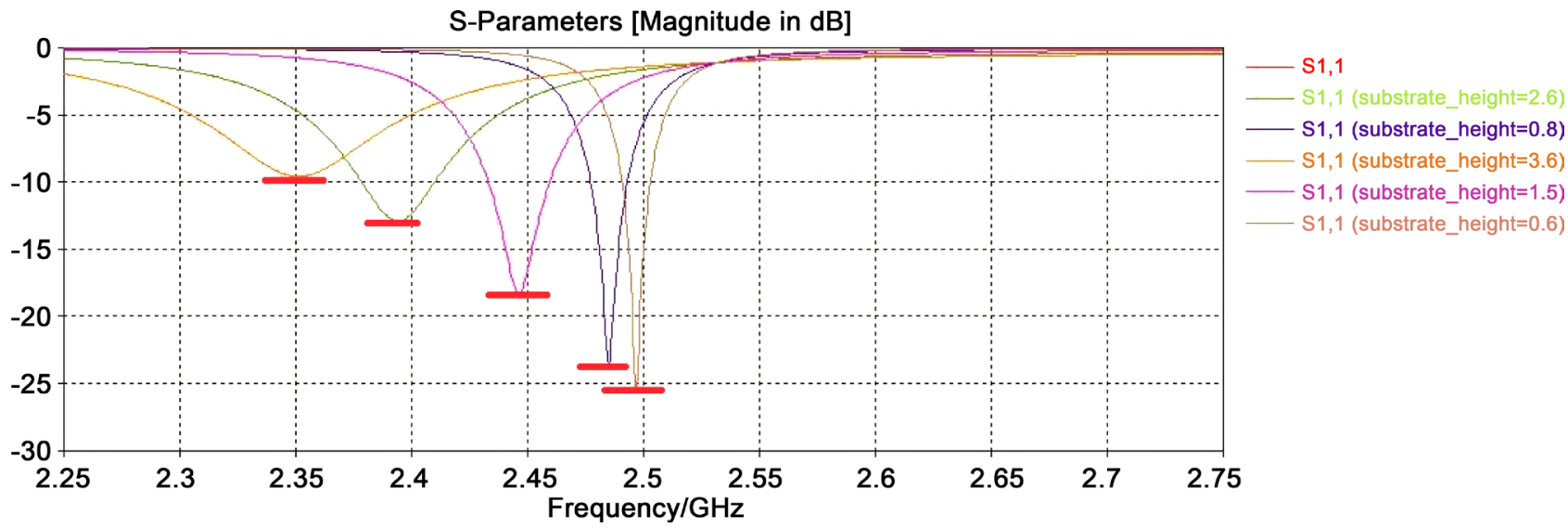

Figure 4. S parameters for circular patch with different substrate height. 




Figure 5. S parameters for Ka band Horn antenna.

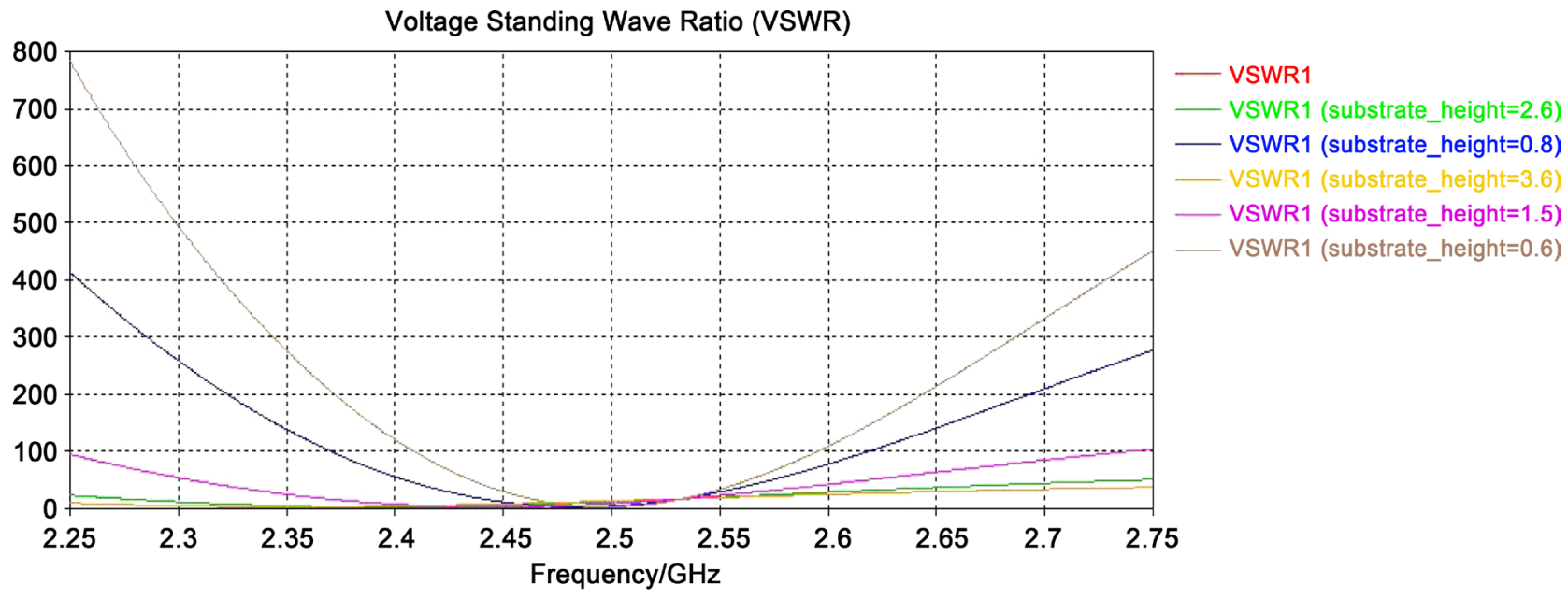

(a)

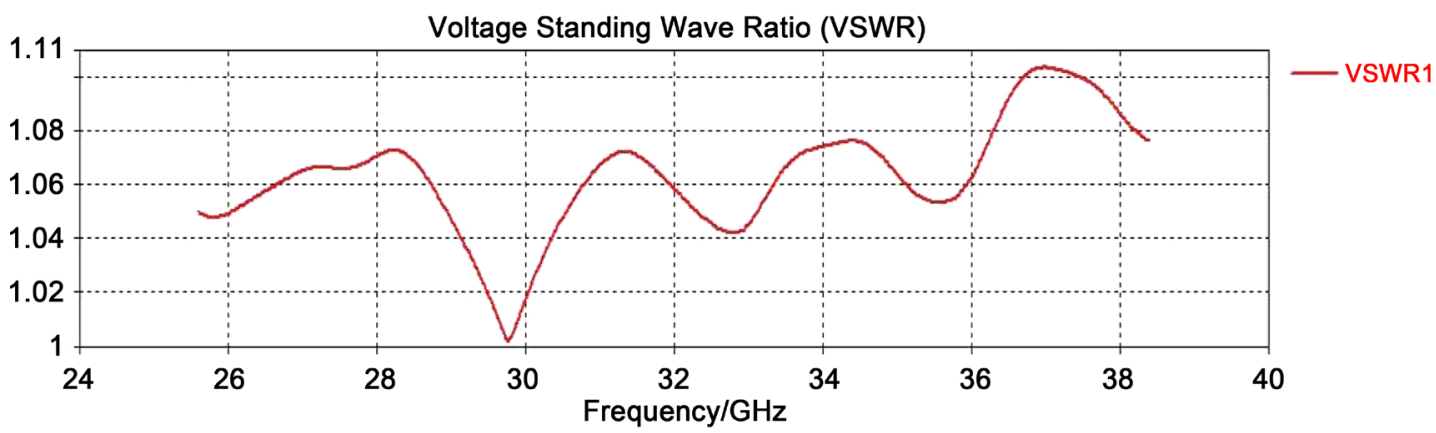

(b)

Figure 6. (a) VSWR for $2.5 \mathrm{GHz}$ circular patch antenna with different substrate height. (b) VSWR for $2.9 \mathrm{GHz}$ horn antenna.

VSWR more power will be delivered to antenna. It's necessary to calculate reflection coefficient Equation (2). If reflection coefficient is given by $\Gamma$ then VSWR can be calculated by Equation (3). Figure 6 shows VSWR for both horn and patch antennas.

$$
\Gamma=\frac{V_{\text {rev }}}{V_{f w d}}
$$

where $\Gamma=$ Complex Number (magnitude \& phase shift of reflection)

$$
V S W R=\frac{\left|V_{\max }\right|}{\left|V_{\min }\right|}=\frac{1+|\Gamma|}{1-|\Gamma|}
$$




\subsection{Radiation Pattern}

In Reference [30], Radiation Pattern is defined as "A mathematical function or a graphical representation of the radiation properties of the antenna as a function of space coordinates. In most cases, the radiation pattern is determined in the far-field region and is represented as a function of the directional coordinates." Antenna transmitted and receiving power can be seen by radiation pattern. Figure 7 shows radiation pattern for $29 \mathrm{GHz}$ Horn antenna. Figure 8 and Figure 9 shows $2.5 \mathrm{GHz}$ circular patch antenna radiation pattern. There is quite difference with different substrate height.

\section{Radio over Fiber Design}

Figure 10 shows system diagram of experiment. On transmitter side we used $\mathrm{S}$ parameters of $2.5 \mathrm{GHz}$ antenna and also $29 \mathrm{GHz} \mathrm{RF}$ signal, both signals are received successful on receiver through $10 \mathrm{Km}$ optical link.

On transmitter side two different frequencies Rf signals are input and on receiver side successful received. Figure 11 shows RoF system diagram designed in Opti System 14. In transmission side two Rf signal generator are used instead of antenna module. In first generator the s parameters were used from $2.5 \mathrm{GHz}$ antenna and $29 \mathrm{GHz}$ antenna s parameters were used in second Rf signal generator. Dual Drive March Zehnder Modulator is used with CW laser and both Rf signals were transmitted through single optical fiber of $10 \mathrm{Km}$ length. Figure 11 shows Eye diagram of both signals successfully received.

\section{Conclusion and Future Work}

We designed $2.5 \mathrm{GHz}$ circular patch and $29 \mathrm{GHz}$ horn antenna for RoF wireless applications. Both antennas show good results. $S$ band circular patch antenna performance is compared in Table 1 [31] [32]. Secondly S parameters and Ka band RF signal were used in RoF system design and on receiver side, received different frequencies signal with eye Diagram shown in Figure 12. In future multi-
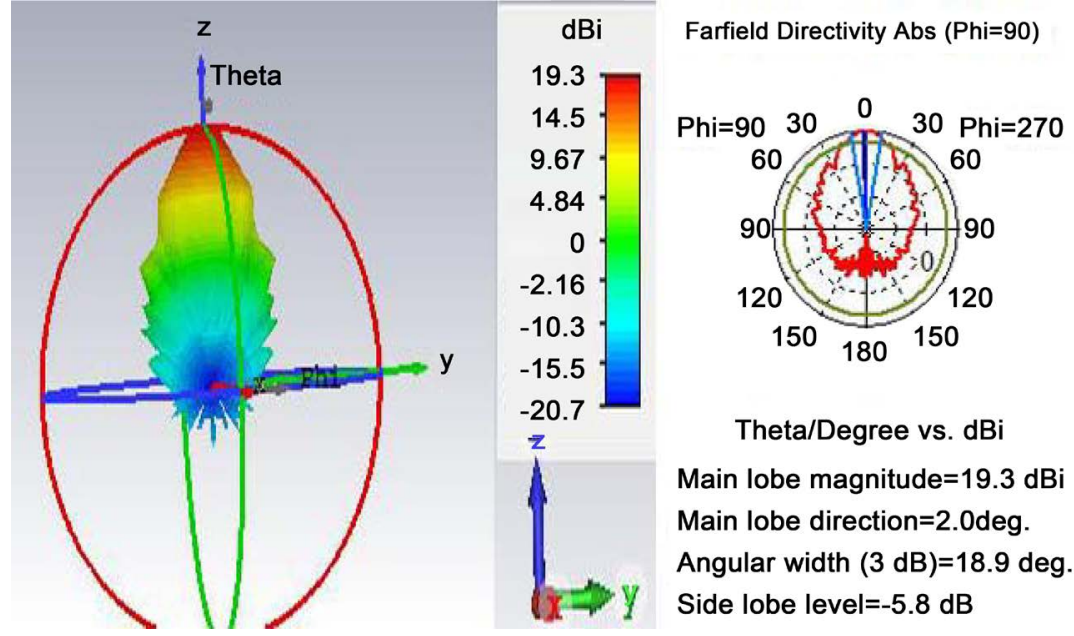

Figure 7. Far Field Directivity for $29 \mathrm{GHz}$ horn antenna. 


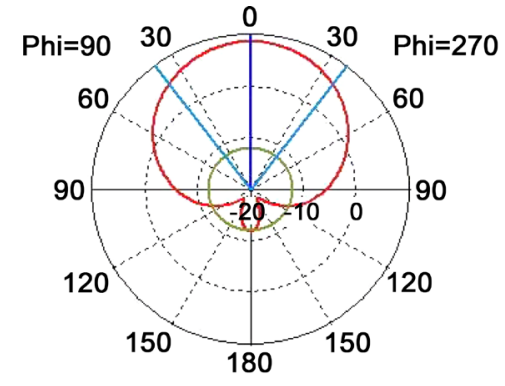

Theta/Degree vs. $\mathrm{dBi}$

Frequency $=2.5 \mathrm{GHz}$

Main lobe magnitude $=8.53 \mathrm{dBi}$

Main lobe direction $=0.0 \mathrm{deg}$.

Angular width $(3 \mathrm{~dB})=74.3 \mathrm{deg}$.

Side lobe level $=-20.5 \mathrm{~dB}$

(a)

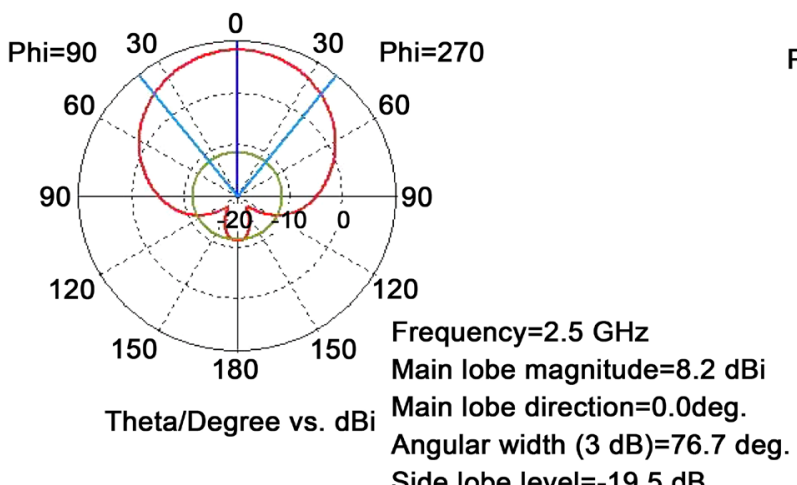

(d)

(b)

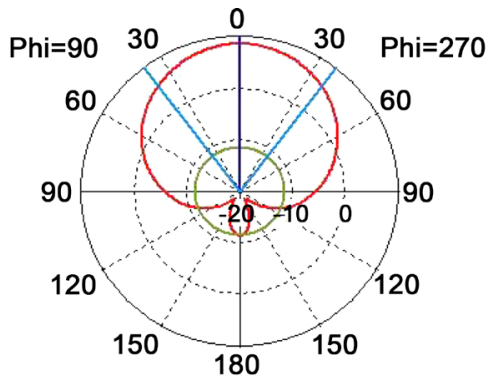

Theta/Degree vs. $\mathrm{dBi}$

Frequency $=2.5 \mathrm{GHz}$

Main lobe magnitude $=8.49 \mathrm{dBi}$

Main lobe direction $=0.0 \mathrm{deg}$.

Angular width $(3 \mathrm{~dB})=74.8 \mathrm{deg}$.

Side lobe level $=-20.0 \mathrm{~dB}$

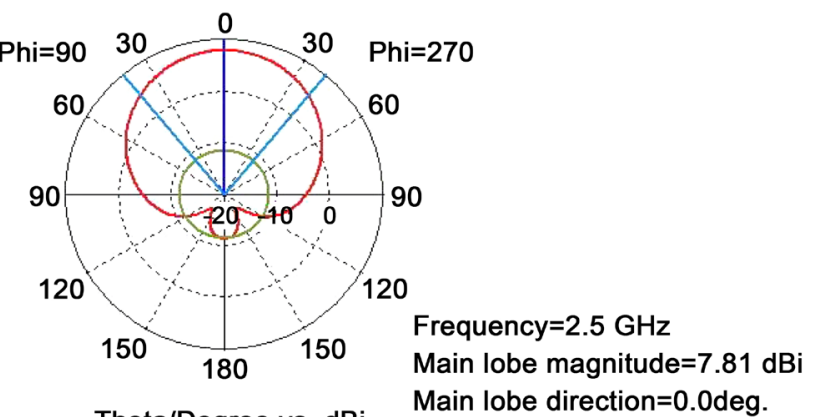

Theta/Degree vs. dBi

(e)

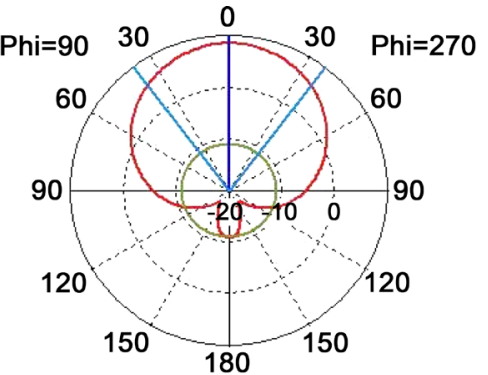

Theta/Degree vs. $\mathrm{dBi}$

Frequency $=2.5 \mathrm{GHz}$

Main lobe magnitude $=8.46 \mathrm{dBi}$

Main lobe direction $=0.0 \mathrm{deg}$.

Angular width $(3 \mathrm{~dB})=74.4 \mathrm{deg}$.

Side lobe level $=-19.3 \mathrm{~dB}$

(c)

Figure 8. Far field for $2.5 \mathrm{GHz}$ antenna with different substrate height. (a) $0.8 \mathrm{~mm}$ (b) $0.6 \mathrm{~mm}$ (c) $1.5 \mathrm{~mm}$ (d) $2.6 \mathrm{~mm}$ (e) $3.6 \mathrm{~mm}$.

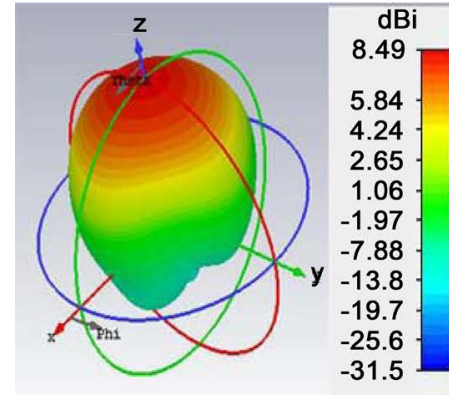

(a)

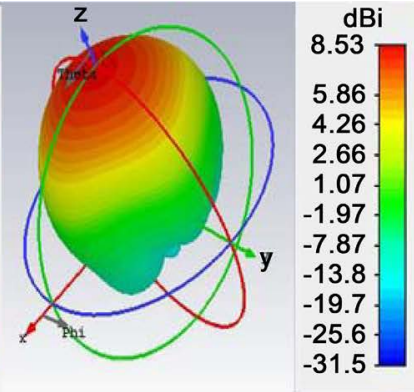

(b)

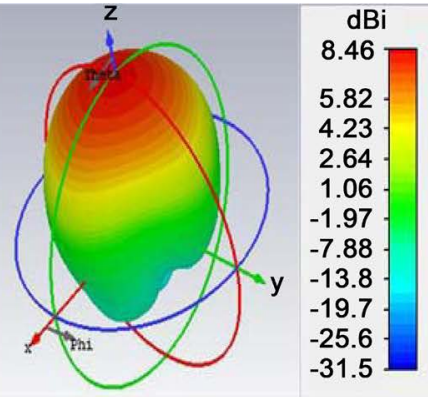

(c)

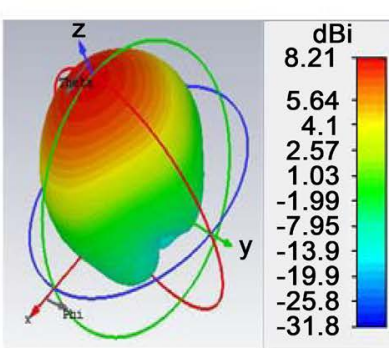

(d)

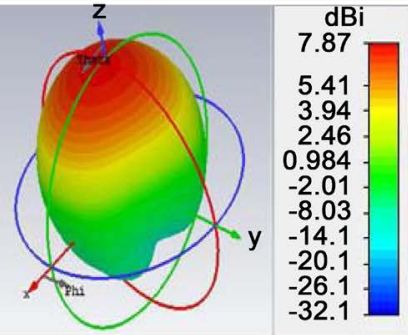

(e)

Figure 9. Radiation Pattern for $2.5 \mathrm{GHz}$ antenna with different substrate height (a) $0.6 \mathrm{~mm}$ (b) $0.8 \mathrm{~mm}$ (c) $1.5 \mathrm{~mm}$ (d) $2.6 \mathrm{~mm}$ (e) $3.6 \mathrm{~mm}$. 


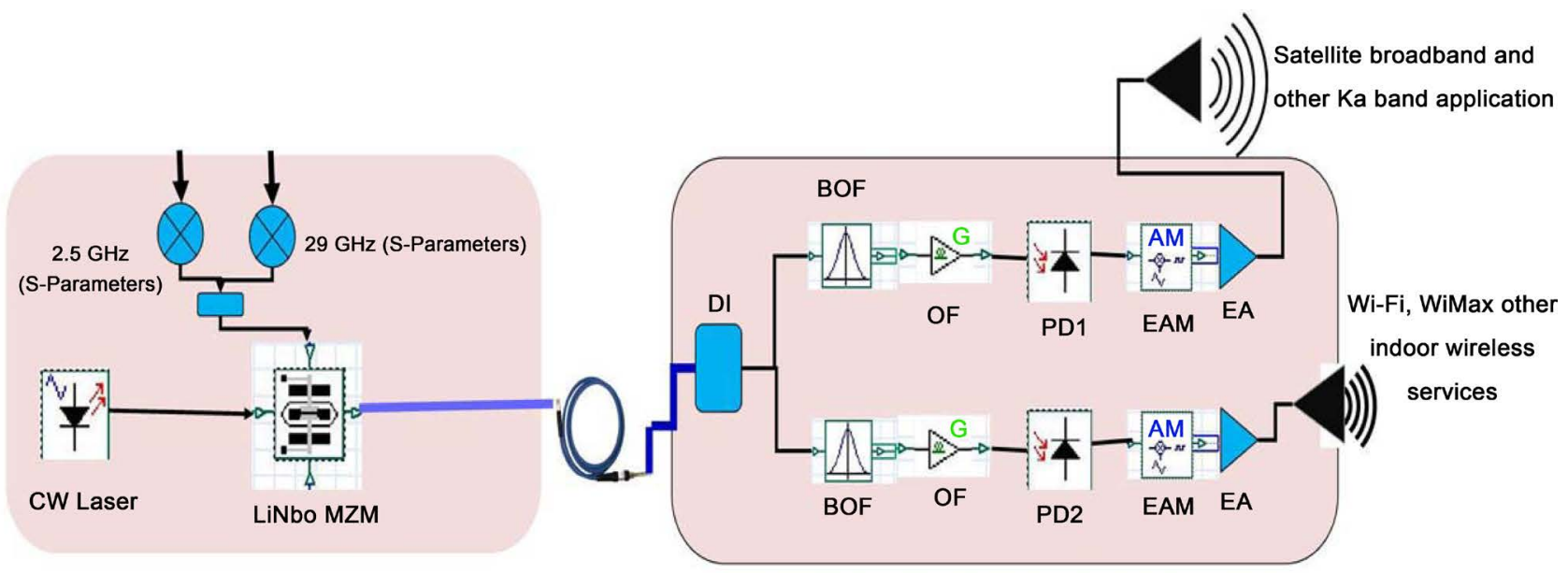

Figure 10. Experiment Radio over Fiber system over view. DI = Delay Interferometer, BOF = Bessel Optical Filter, OA = Optical Amplifier, $\mathrm{PD}=$ Photodiode, $\mathrm{EAD}=$ Electrical Amplitude Demodulator, $\mathrm{EAD}=$ Electrical Amplitude Demodulator.

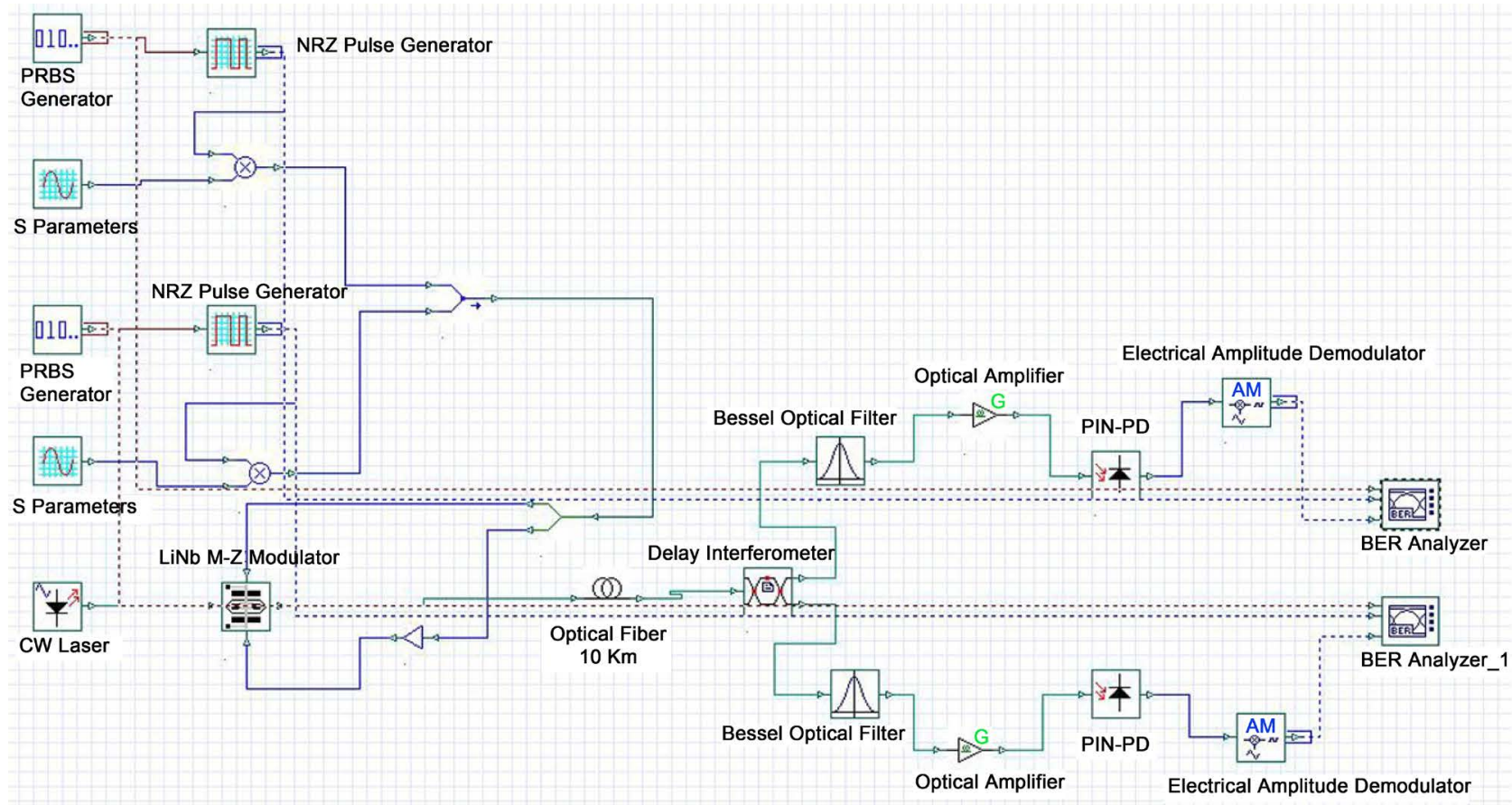

Figure 11. Multi-Frequency Radio over Fiber System.

Table 1. Far-Field Comparison.

\begin{tabular}{ccc}
\hline No. & Frequency $(\mathrm{Fo})$ & Far-Field $(\mathrm{dBi})$ \\
\hline$[31]$ & $2.5 \mathrm{GHz}$ & 8.1 \\
{$[32]$} & $2.5 \mathrm{GHz}$ & 4.53 \\
Presented & $2.5 \mathrm{GHz}$ & 8.53 \\
\hline
\end{tabular}






(a)



(b)

Figure 12. Eye diagram for $2.5 \mathrm{GHz}$ and $29 \mathrm{GHz}$ received signal.

band antennas will be designed and parameters will be using in RoF system. As RoF is integrated with multi frequencies applications, So on system level it's important to consider emission wavelength of laser, length of fiber and transmitted frequencies for better signal integrity. RoF is easy to expand and flexible. RoF will be core technology for future indoor and outdoor wireless applications.

\section{Acknowledgements}

This research is supported by CAS-TWAS. We thank MESIC research fellows for their support in all means.

\section{References}

[1] Liu, J., Beals, M., Pomerene, A., Bernardis, S., Sun, R., Cheng, J., et al. (2008) Waveguide-Integrated, Ultralow-Energy GeSi Electro-Absorption Modulators. Nature Photonics, 2, 433-437. https://doi.org/10.1038/nphoton.2008.99

[2] Kajima, S., Tsukamoto, K. and Komaki, S. (1996) Proposal of Fiber-Optic Radio Highway Networks Using CDMA Method. IEICE Transactions on Electronics, 79, 111-117.

[3] Way, W. (1993) Optical Fiber-Based Microcellular Systems: An Overview (Special Issue on Fiber-Optic Microcelluler Radio Communication System and Their Technologies). IEICE Transactions on Communications, 76, 1091-1102.

[4] Kashif, R. and Lin, F. (2015) Signal Integrity Problems in Electronic Designing. Microwave Conference (APMC), Asia-Pacific, Nanjing, 6-9 December 2015, 1-3. https://doi.org/10.1109/APMC.2015.7412979

[5] Al-Raweshidy, H. and Komaki, S. (2002) Radio over Fiber Technologies for Mobile Communications Networks: Artech House.

[6] Karthikeyan, R. and Prakasam, S. (2013) A Survey on Radio over Fiber (RoF) for 
Wireless Broadband Access Technologies. International Journal of Computer Applications, 64, 14-19.

[7] Lach, E., Schuh, K. and Schmidt, M. (2005) Application of Electroabsorption Modulators for High-Speed Transmission Systems. Ultrahigh-Speed Optical Transmission Technology, Springer, New York, 347-377. https://doi.org/10.1007/s10297-005-0032-6

[8] Ji, W. and Chang, J. (2013) Design of WDM-RoF-PON for Wireless and Wire-Line Access with Source-Free ONUs. Journal of Optical Communications and Networking, 5, 127-133. https://doi.org/10.1364/JOCN.5.000127

[9] Jiang, W.-J., Lin, C.-T., Shih, P.-T., He, L.-Y.W., Chen, J. and Chi, S. (2010) Simultaneous Generation and Transmission of $60-\mathrm{GHz}$ Wireless and Baseband Wireline Signals with Uplink Transmission Using an RSOA. IEEE Photonics Technology Letters, 22, 1099-1101. https://doi.org/10.1109/LPT.2010.2050466

[10] Hsueh, Y.-T., Jia, Z., Chien, H.-C., Yu, J. and Chang, G.-K. (2009) A Novel Bidirectional 60-GHz Radio-Over-Fiber Scheme with Multiband Signal Generation Using a Single Intensity Modulator. IEEE Photonics Technology Letters, 21, 1338-1340. https://doi.org/10.1109/LPT.2009.2026061

[11] Hsueh, Y.-T., Huang, M.-F., Fan, S.-H. and Chang, G.-K. (2011) A Novel Lightwave Centralized Bidirectional Hybrid Access Network: Seamless Integration of RoF with WDM-OFDM-PON. IEEE Photonics Technology Letters, 23, 1085-1087. https://doi.org/10.1109/LPT.2011.2156402

[12] Ma, J., Yu, J., Yu, C., Xin, X., Zeng, J. and Chen, L. (2007) Fiber Dispersion Influence on Transmission of the Optical Millimeter-Waves Generated using LN-MZM Intensity Modulation. Journal of Lightwave Technology, 25, 3244-3256. https://doi.org/10.1109/JLT.2007.907794

[13] Jia, Z., Yu, J., Ellinas, G. and Chang, G.-K. (2007) Key Enabling Technologies for Optical-Wireless Networks: Optical Millimeter-Wave Generation, Wavelength Reuse, and Architecture. Journal of Lightwave Technology, 25, 3452-3471. https://doi.org/10.1109/JLT.2007.909201

[14] Li, H., Hajipour, J., Attar, A. and Leung, V.C. (2011) Efficient HetNet Implementation using Broadband Wireless Access with Fiber-Connected Massively Distributed Antennas Architecture. IEEE Wireless Communications, 18, 72-78.

[15] Chang, G.-K., Jia, Z., Yu, J., Chowdhury, A., Wang, T. and Ellinas, G. (2008) Super Broadband Optical Wireless Access Technologies. Optical Fiber Communication Conference, OThD1. https://doi.org/10.1109/OFC.2008.4528441

[16] Sauer, M., Kobyakov, A. and George, J. (2007) Radio over Fiber for Picocellular Network Architectures. Journal of Lightwave Technology, 25, 3301-3320. https://doi.org/10.1109/JLT.2007.906822

[17] Shinde, P.N. and Shinde, J.P. (2015) Design of Compact Pentagonal Slot Antenna with Bandwidth Enhancement for Multiband Wireless Applications. AEU-International Journal of Electronics and Communications, 69, 1489-1494.

[18] Shinde, J.P. and Shinde, P.N. (2016) M-Shape Electromagnetic-Bandgap Structures for Enhancement in Antenna Performance. AEU-International Journal of Electronics and Communications, 70, 842-849.

[19] Doraisingam, Y. (2007) Bandwidth Enhancement of Microstrip Antenna for Wireless Local Area Network Applications. School of Graduate Studies, Universiti Putra Malaysia.

[20] Shen, L., Long, S., Allerding, M. and Walton, M. (1977) Resonant Frequency of a 
Circular Disc, Printed-Circuit Antenna. IEEE Transactions on Antennas and Propagation, 25, 595-596. https://doi.org/10.1109/TAP.1977.1141643

[21] Derneryd, A. (1979) Analysis of the Microstrip Disk Antenna Element. IEEE Transactions on Antennas and Propagation, 27, 660-664. https://doi.org/10.1109/TAP.1979.1142159

[22] Long, S. and Walton, M. (1979) A Dual-Frequency Stacked Circular-Disc Antenna. IEEE Transactions on Antennas and Propagation, 27, 270-273. https://doi.org/10.1109/TAP.1979.1142078

[23] Fonseca, S.D.A. and Giarola, A. (1984) Microstrip Disk Antenna, Part 1: Efficiency of Space Wave Launching. IEEE Transactions on Antennas and Propagation, 32, 561-567.

[24] Fonseca, S.D.A. and Giarola, A. (1984) Microstrip Disk Antennas, Part II: The Problem of Surface Wave Radiation by Dielectric Truncation. IEEE Transactions on Antennas and Propagation, 32, 568-573.

[25] Aberle, J.T. and Zavosh, F. (1994) Analysis of Probe-Fed Circular Microstrip Patches Backed by Circular Cavities. Electromagnetics, 14, 239-258. https://doi.org/10.1080/02726349408908382

[26] Zavosh, F. and Aberle, J.T. (1994) Infinite Phased Arrays of Cavity-Backed Patches. IEEE Transactions on Antennas and Propagation, 42, 390-398. https://doi.org/10.1109/8.280726

[27] Aberle, J.T. and Pozar, D.M. (1990) Analysis of Infinite Arrays of One- and Two-Probe-Fed Circular Patches. IEEE Transactions on Antennas and Propagation, 38, 421-432. https://doi.org/10.1109/8.52260

[28] Kaufman, C. (1995) Rocky Mountain Research Lab. Private Communication, Boulder.

[29] Lai, T., Mahadi, W.N.L. and Soin, N. (2008) Circular Patch Microstrip Array Antenna for Ku-Band. World Academy of Science, Engineering and Technology, 48, 298-302.

[30] Balanis, C.A. (2016) Antenna Theory: Analysis and Design. John Wiley \& Sons.

[31] Dwivedi, S., Rawat, A. and Yadav, R.N. (2013) Design of U-Shape Microstrip Patch Antenna for WiMAX Applications at $2.5 \mathrm{GHz}$. 10 th International Conference on Wireless and Optical Communications Networks, 1-5.

[32] Koutinos, A.G., Ioannopoulos, G.A., Chryssomallis, M.T., Kyriacou, G.A. and Caratelli, D. (2017) Bandwidth Enhancement of a Supershape Patch Antenna using Multiple Feeding Technique. International Workshop on Antenna Technology: Small Antennas, Innovative Structures, and Applications, 211-214. https://doi.org/10.1109/IWAT.2017.7915360 
Submit or recommend next manuscript to SCIRP and we will provide best service for you:

Accepting pre-submission inquiries through Email, Facebook, LinkedIn, Twitter, etc. A wide selection of journals (inclusive of 9 subjects, more than 200 journals)

Providing 24-hour high-quality service

User-friendly online submission system

Fair and swift peer-review system

Efficient typesetting and proofreading procedure

Display of the result of downloads and visits, as well as the number of cited articles Maximum dissemination of your research work

Submit your manuscript at: http://papersubmission.scirp.org/

Or contact ojapr@scirp.org 